\title{
Notification of Regulatory Identification Number Document
}

National Cancer Institute

\section{Source}

National Cancer Institute. Notification of Regulatory Identification Number Document. NCI Thesaurus. Code C115717.

Records that contain a unique identification number assigned by a regulatory agency, and are used to identify a clinical trial or the trial's level in a region. 